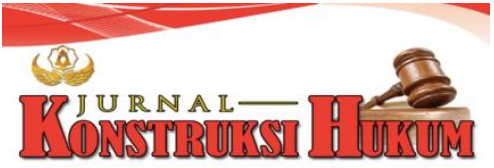

\title{
TINDAKAN PREVENTIF KEPOLISIAN DALAM MENANGGULANGI PENYALAHGUNAAN MINUMAN KERAS (MIRAS) DI WILAYAH HUKUM POLDA BALI
}

\author{
Anak Agung Satria Adhi Wiguna, Anak Agung Sagung Laksml Dewi, Luh Putu Sury Ani \\ Fakultas Hukum, Universitas Warmadewa, Denpasar - Bali, Indonesia \\ gungsatria1510@gmail.com, laksmidewii29@gmail.com, putusuryani099@gmail.com
}

\begin{abstract}
Abstrak
Alkohol merupakan stimulan karena unsur yang dikandung dapat meremajakan tubuh, namun pandangan ini salah karena stimulan hanya bersifat sementara. Orang yang minum alkohol kurang memiliki rasa pencegahan atau penghambatan. penelitian yang digunakan dalam penelitian ini adalah jenis penelitian empiris, dimana penelitian dilakukan terhadap kondisi masyarakat atau lingkungan sekitar yang sebenamya, dengan tujuan untuk menemukan fakta atau permasalahan hukum yang ada. Melihat kendala yang dihadapi polisi dalam menerapkan "UU Penyalahgunaan Alkohol" di wilayah kepolisian wilayah Bali, banyak faktor yang menyebabkan Polda Bali menghadapi banyak kendala dalam penerapan Undang-Undang Anti Penyalahgunaan Alkohol (Miras), termasuk faktor internal dan ekstemal yang membuat Bali. Berdasarkan latar belakang masalah yang diuraikan dapat disimpulkan bahwa tindakan yang telah dilakukan polisi untuk mengatasi penyalahgunaan alkohol di wilayah Polda Bali. Dalam yurisdiksi Polda di Bali, hambatan yang dihadapi polisi dalam menegakkan hukum tentang penyalahgunaan alkohol.
\end{abstract}

Kata Kunci: Penyalagunaan Miras, Tindakan Preventif.

\begin{abstract}
Alcohol is a stimulant because the elements it contains can rejuvenate the body, but this view is wrong because stimulants are only temporary. People who drink alcohol lack a sense of prevention or inhibition.People who drink alcohol lack a sense of prevention or inhibition. The research used in this research is a type of empirical research, where research is carried out on the real condition of the community or environment, with the aim of finding facts or existing legal problems. Seeing the obstacles faced by the police in implementing the "Alcohol Abuse Law" in the Bali police area, many factors have caused the Bali Police to face many obstacles in implementing the Anti Alcohol Abuse (Miras) Law, including internal and external factors that make Bali. Based on the background of the problems described, it can be concluded that the actions taken by the police to address alcohol abuse in the Bali Police area. Within the jurisdiction of the Polda in Bali, the obstacles faced by the police in enforcing laws regarding alcohol abuse.
\end{abstract}

Keywords: Alcohol Abuse, Preventive Action.

\section{PENDAhULUAN}

Kondisi lingkungan yang berubah dengan cepat telah menyebabkan semakin longgamya norma dan sanksi sosial, dan berbagai subkultur dan budaya asing saling bertentangan, faktor - faktor tersebut diatas mengakibatkan terjadinya peri laku kriminal. Irwanti (2012:35) Akibat kebiasaan minum ini akan berdampak buruk bagi masyarakat, ekonomi, dan kesehatan masyarakat di wilayah tersebut. Misalnya, dampaknya dimulai dengan meningkatnya kasus kriminal, terutama perkelahian pemuda, yang mengganggu masyarakat sekitar, jurang peminum lansia dan muda atau peminum daerah, dan peningkatan kemiskinan. Berdasarkan definisi di atas maka perlu ditetapkan ketentuan yang berkaitan dengan peredaran minuman beralkohol, dengan ketentuan sebagai berikut: Minum minuman keras merupakan hal yang cukup banyak di kalangan masyarakat Indonesia, khususnya pria dewasa. Alkohol dapat meningkatkan stigma terhadap vitalitas dan perhatian manusia. Bahkan di beberapa daerah, minum sudah menjadi budaya. (R. Soesilo, 1996:220) mengartikan minuman keras sebagai minuman beralkohol yang digunakan sebagai minuman santai. Tujuan minuman beralkohol dapat dijadikan minuman kasual bertujuan agar para pecandu alkohol dapat melepas stres dan penawar. (Hari Sasangka 2003: 107) Jelaskan bahwa alkohol (alcohol) tidak dapat berhenti diminum tanpa menimbulkan konsekuensi yang merugikan bagi diri Anda sendiri. la menjadi tergantung pada alkohol 
secara fisik dan psikologis. Minuman beralkohol dapat diklasifikasikan sebagai obat psikotropika, yaitu zat atau obat alami dan sintetis, daripada obat narkotika, yang memiliki efek psikoaktif melalui efek selektif pada sistem saraf pusat, sehingga menyebabkan perubahan signifikan pada aktivitas dan perilaku mental.

Alkohol adalah obat yang mengharnbat aktivitas sistem saraf pusat. Orang yang minum alkohol kurang memiliki rasa pencegahan atau pengharnbatan. Dia tidak memiliki rasa tanggung jawab atau kecemasan. Kemabukan mengancarn kendali fisik dan mental. Pecandu alkohol harus terlebih dahulu meminum lebih banyak alkohol, yang pada akhirnya akan menimbulkan hangover (rasa sakit keesokan paginya setelah minum terlalu banyak. Dapat disembuhkan dengan meminumnya kembali, agar ia tidak lepas dari alkohol). Pengguna merasa tegas dan euforia, efek penghambatannya kurang, jadi dia berbicara lebih banyak dari biasanya, merasa lebih bebas dalam hubungan formal antar teman, wajahnya memerah karena tekanan darah, dan detak jantungnya meningkat. Orang yang minum alkohol mungkin merasa cemas, berperilaku bingung, tidak dapat berbicara dengan jelas, dan berjalan dengan goyah. Budaya minum memiliki sejarah yang panjang, semakin lama perubahan nilai alkohol di masyarakat baik secara hukum maupun agama, minum dianggap tidak wajar dan wajar bagi keduanya. Karena faktor harga yang murah dan minimnya sosialisasi bahaya kesehatan dari minuman beralkohol, fenomena yang terjadi di masyarakat dalam ha! alkohol ini banyak menyebar di masyarakat.

Laminting ( 1984: 173-174) Upaya kerjasama antara Polri dengan dukungan komponen masyarakat telah mengatasi distribusi minuman beralkohol dan darnpaknya, namun berbagai upaya yang dilakukan oleh kepolisian dan komponen masyarakat belum mencapai hasil yang maksimal, yang dapat dicapai melalui banyaknya perkara. membuktikan. Kasus kejahatan -Minum. Selain kebutuhan Polri untuk berperan aktif dan tegas, keburuhan akan penerapan kebijakan resmi untuk menangani peredaran alkohol di masyarakat sangat bernilai bagi kinerja kinerja Polri. Berdasarkan penjelasan diatas, maka dapat dirumuskan tujuan dari penelitian ini yakni untuk mengetahui tindakan yang telah dilakukan polisi untuk mengatasi penyalahgunaan alkohol. Selain itu, untuk mengetahui hambatan yang dihadapi polisi dalam menegakkan hukum alkohol.

\section{METODEPENELITIAN}

(Notoatmodjo, 2010) mendefinisikan pengetahuan sebagai hasil pengindraan manusia, atau hasil tahu seseorang terhadap objek melalui Indra yang dimilikinya (mata, hidung, telinga, dan sebagainya), ehingga menghasilkan pengetahuan yang dipengaruhi oleh intensitas perhatian dan persepsi terhadap objek. Metode penyelesaian masalah yang digunakan dalam penelitian ini adalah metode hukum sosiologis yang berkaitan dengan penelitian yang diteliti. Metode yuridis sosiologi adalah studi tentang siruasi aktual masyarakat atau lingkungan sekitarnya,dengan tujuan untuk menemukan fakta atau masalah yang ada, mengarah pada identifikasi, dan akhirnya untuk menyelesaikan masalah. Sumber data dimana penulis memperoleh data dalarn penelitian ini yaitu data asli dan data pembantu yang digunakan. 1). Data Utarna Data utama terdiri dari hasil wawancara langsung dari narasumber dan narasumber yang bertujuan untuk mendapatkan pemahaman yang lebih jelas tentang penyalahgunaan alkohol di wilayah yurisdiksi Polda Bali. 2). Data Sekunder Data Sekunder adalah sumber data penelitian yang diperoleh melalui media perantara atau secara tidak langsung berupa buku, catatan, bukti atau arsip yang ada (diterbitkan dan tidak diterbitkan secara umum), termasuk bahan hukum utama dan sekunder. Bahan hukum meliputi literatur, kamus dan karya ilmiah lain yang berkaitan dengan subjek penelitian. Untuk memperoleh data yang diharapkan, penulis mengumpulkan data dengan dua cara yaitu melalui metode penelitian pustaka dan metode penelitian lapangan: metode penelitian pustaka dan metode penelitian pustaka. Penelitian yang mengumpulkan data dalam jumlah besar dengan membaca dan menelusuri literatur yang terkait dengan masalah yang dibahas. Metode penelitian lapangan (field research), metode penelitian lapangan (field research) yaitu melakukan penelitian di tempat, melalui observasi langsung dengan dua cara yaitu: 1) wawancara (interview) yaitu penulis berhubungan langsung dengan masalah Semua pihak melakukan tanyajawab. 2) Dokumen, yairu penulis memperoleh data dengan melihat dokumen dan arsip yang disediakan oleh pihak terkait. 


\section{HASIL DAN PEMBAHASAN}

Alkohol adalah suatu zat yang bekerja secara selektif, teutama pada otak, sehingga dapat menimbulkan perubahan pada perilaku, emosi, kognitif, persepsi, kesadaran seseorang yang apabila digunakan dapat menimbulkan kecanduan atau ketergantungan (Widodo, 2004). Danrivanto Budhijanto (2014: 33) erbicara tentang alkohol seperti berbicara tentang dilema. Di satusisi, alkohol dapat menimbulkan masalah kesehatan dan sosial. Di bidang kesehatan, penurunan produktivitas dan meningkatkan biaya perawatan dan pengobatan dapat disebabkan oleh alkohol. Di bidang sosial telah menyebabkan ketidakharmonisan dalarn hubungan keluarga, meningkatnya kecelakaan lalu lintas, dan meningkatnya kejahatan sosial.

Rijkschroeff (2001:18) Sejumlah kecil etanol mempengaruhi otak, perasaan diubah menjadi lebih baik, sedangkan jumlah besar efek etanol pada otak menjadi berbahaya. Orang yang min um ban yak alkohol kehilangan kendal i atas diri mereka sendiri dan bahkan mungkin kehilangan kesadaran. Kebiasaan minum telah ada di semua negara sejak zaman kuno. Dalam cerita kuno, banyak orang suka minum minuman beralkohol yang memabukkan. Alkohol (alkohol) adalah minuman yang mengandung alcohol, yang membuat ketagihan dan dapat membahayakan pemakainya karena mempengaruhi pikiran, emosi dan perilaku, serta merusak fungsi organ. Hasilnya memberikan stimulasi, ketenangan, menghilangkan rasa sakit, anestesi dan membuat Anda bahagia.

Mengkonsumsi alkohol setiap hari dan dalam jumlah yang makin meningkat maka akan terjadi toleransi, ang dibagi dalam 3 bentuk yaitu behavioral tolerance yaitu refleksi kemampuan seseorang unntuk belajar dalam tugas afektif oleh alcohol, Tolerans farmakokinetik yaitu produksi dehidrogenese alcohol dan mikrosom system reticulum endoplasmik meningkat. Tolerans seluler yaitu adaptasi system neuron akibat peningkatan jumlah konsumsi alcohol (Soetjiningsih, 2010). Minuman beralkohol mungkin berbahaya bagi kesehatan. Penyalahgunaan alkohol jangka panjang secara langsung mempengaruhi semua lagian otak, termasuk hipotalamus. Orang yang mabuk berat juga menyerap begitu banyak kalori dari alkohol sehingga mereka bisa makan tanpa rangsangan. Keadaan ini akan menyebabkan asupan vitamin dalam tubuh tidak mencukupi. Dalam kasus yang ekstrim, kondisi ini dapat berkembang menjadi demensia yang merupakan salah satu sindrom otak organik. Namun, efek ini biasanya baru terlihat setelah bertahun-tahun. Alkohol menimbulkan ketergantungan (kecenduan) pada pemakainya. Makin sering memakai minum minuman beralkohol, makin besar ketergantunganya sehingga pada suatu saat tidak bisa melepaskan dirilagi (Sarwono, 2008).

Abdul Rozak dan Wahdi Sayati (2006: 17) Petugas Kepolisian Daerah Polda Bali rutin memeriksa pedagang wine, mengimbau pedagang wine untuk menjaga tingkat wine yang dijual, terus mengecek status wine yang didapat dari pengepul, dan mengiklankan bahaya minum kepada pembeli wine Dan resiko. Karena kehadiran polisi di distrik hukum Borda di Bali untuk menyelesaikan masalah penyalahgunaan alkohol, penjual semakin berhati-hati setiap kali menjual alkohol, dan penjual juga memahami perilaku legal alkohol.

Tentunya banyaknya acara cocktail di masyarakat didukung oleh beberapa faktor. Tenrunya tidak hanya jumlah yang hadir yang hadir, tetapi kesulitan orang minum membuat sebagian orang lebih mudah unruk minum. Jika kita melihat sedikit acara, cocktail party ini diadakan oleh sekelompok siswa SMA yang sudah berusia belasan tahun. Ini karena orang dapat dengan mudah membeli rninuman keras di toserba. Pemerintah mengizinkan bir dan produk beralkohol lainnya dengan kandungan alkohol kurang dari 5\% untuk dijual gratis di pasar kecil di dekat kawasan pemukiman.

Faktor lainnya bagi pecandu alkohol yang marak di masyarakat adalah beredamya minuman beralkohol ilegal di masyarakat. Adapun Minuman keras yang diperbolehkan oleh pemerintah adalah dengan kandungan maksimal 55\% dan peredarannya diatur dengan peraturan pemerintah. Hal ini menunjukkan bahwa pemerintah telah mernbentuk mekanisme pengawasan peredaran alkohol agar efek minuman tersebut dapat dikendalikan. Tentu saja, pembuatan ilegal mencegah produk dijual secara legal, sehingga minuman keras jenis ini biasanya dijual di minuman keras atau warungjamu tanpa izin pemerintah. Hal ini tentu saja membuat pengawasan pemerintah semakin sulit. Apalagi, minimnya pengawasan membuat pemerintah kesulitan mengendalikan dampak negatifnya.

Dalam melakukan kegiatan kepolisian tersebut, Kepolisian Daerah Bali berpegang pada prinsip-prinsip sebagai berikut: Kawasan Bali merupakan kawasan yang aman, sehingga tidak akan 
mengganggu kegiatan wisata. Sedangkan faktor yang mempengaruhi kelancaran pelaksanaan tindakan pengendalian alkohol adalah pemahaman agama.Keyakinan beragama memperkuat keyakinan, sehingga tidak mudah terjerumus ke dalam emosi negatif, dan dapat membantu polisi dalam mengatasi tugas penyalahgunaan alkohol, meningkatkan kesadaran masyarakat akan bahaya minuman keras, dan berkoordinasi lintas departemen . Bekerja sama dengan instansi terkait, dan keberadaan peraturan perundang-undangan menjadi dasar hukumnya.

Berdasarkan hasil wawancara saya dengan penyidik Bareskrim Polresta Denpasar I Nyoman Wiranata, pada pukul 11.30 tanggal 17 Oktober 2020, disebutkan faktor ekstemal atau eksternal, yaitu tokoh masyarakat yang berbasis di wilayah Bali. Polisi menggunakan penyalahgunaan alkohol sebagai alasan untuk menghindarkan aparat kepolisian dari harnbatan-hambatan dalam menangani penyalahgunaan alkohol Dengan memberikan sosialisasi, konsultasi, pembinaan, pengendalian dan pengawasan maka masyarakat dan kendala yang ada di masyarakat yaitu kurangnya kesadaran masyarakat merupakan para pelaku penyalahgunaan alkohol oleh Polda Bali. Kendala untuk mencapai kondisi terbaik, agar masyarakat tidak menyalahgunakan dan ikut serta mengatasi penyalahgunaan alkohol.

\section{SIMPULAN DAN SARAN}

\section{Simpulan}

Dari penjelasan pendahuluan sampai dengan hasil penelitian dan pembahasan, maka dapat disimpulkan bahwasannya kepolisian dalam menanggulangi penyalahgunaan minuman keras (miras) di wilayah hukum Polda Bali menyatakan bahwa minuman beralkohol menyebabkan dampak buruk yang berkepanjangan pada kesehatan pecandu minuman keras dan dan dapat berpengaruh pada otak pecandu, termasuk pada hipotalamus pemabuk berat memiliki banyak kalori yang terdapat dalam alkohol sehingga pecandu tidak mempunyai nafsu makan keadaan ini menyebabkan kandungan vitamin yang sedikit masuk ke dalam tubuh dan efek paling keras pada kondisi ini dapat menyebabkan demensia merupakan sindrom otak organik tetapi efek ini akan timbul setelahnya. Karena keberadaan polisi di wilayah hukum Borda Bali untuk menyelesaikan masalah penyalahgunaan alkohol, penjual lebih berhati-hati dan berhati-hati setiap kali menjual rninuman keras, dan penjual memahami perilaku hukum terkait alkohol. Melihat kendala yang dihadapi polisi dalam menegakkan Undang Undang Penyalahgunaan Alkohol (Alkohol) di wilayah kepolisian Daerah Bali, ada banyak faktor yang menyebabkan kepolisian di Wilayah Bali menghadapi banyak kendala dalam menegakkan Undang-Undang Penyalahgunaan Alkohol (Miras). Yaitu: Kepolisian di wilayah Bali banyak menemui kendala faktor internal dan eksternal.Adapun upaya Polda Bali dalam menangani tindak pidana akibat minum alkohol meliputi upaya, aksi mogok kerja, pencegahan, penindasan dan pengobatan.

\section{Saran}

Dalam hal ini, Polda Bali harus bekerja lebih keras lagi untuk memberantas peredaran gelap alkohol di Bali untuk mencegah generasi muda kita berhubungan dengan alkohol, karena sekecil apapun anggur putih tetap akan mempengaruhi perkembangan generasi muda di Bali, karena Ada banyak masalah dengan minuman keras, dari kekerasan hingga pemerkosaan. Untuk mengatasi masalah penyalahgunaan alkohol, polisi harus berani dan berani rnengeluarkan peraturan tentang penyalahgunaan alcohol. Pasalnya, pihak penegak hokum Polda Bali harus memiliki sarana dan prasarana yang memadai agar tidak ada kendala yang dapat menghambat penyalahgunaan alcohol oleh aparat penegak hukum dalam melakukan tindakan. Polisi juga harus berinteraksi dengan orangorang yang minum alkohol secara teratur agar dapat memahami efek alkohol.

\section{DAFTAR PUSTAKA}

Danrivanto, B. (2014). Teori Hukum Konvergensi. Refika Aditama.Bandung. Hari, S. (2004). Narkotika dan Psikotropika dalam Hukum Pidana. CY. Mandar Maju. Bandung. Laminting. (1984). Dasar-Dasar Hukum Pidana Indonesia. Sinar Baru. Bandung. Notoatmodjo, S. (2003). Pendidikan dan Perilaku Kesehatan. Rineka Cipta. Jakarta. Rijkhoroeff. (2001) .Sosiologi, Hukum dan Sosiologi Hukum.Mandar Maju. Bandung. R.Soesilo. (1996). Kitab Undang-Undang Hukum Pidana (KUHP). Politea.Bogor. Said Irwanti. (2012). Analisis Problem Sosial. Alauddin University Press. Makassar. 
Sarwono. (2008). Psikologi Remaja. PT Raja Grafindo Prasada. Jakarta

Soetjiningsih. (2010). Tumbuh Kembang Remaja Dan Permasalahannya. Sagung Seto. Jakarta.

Widodo, A. (2004). Tinjauan Sosilogi Kesehatan Mengenai Kebiasaan Minum Minuman Keras ("Ciu Bekonang”) dan Upaya Penanggulaangannya. Vol 8(1).Sukoharjo. 